\title{
O leitor e as mudanças no processo de sig̊nificação: uma análise de A Rainha dos Cárceres da Grécia, de Osman Lins
}

Carolina Duarte Damasceno

RESUMO: Este artigo tem como propósito refletir sobre o papel do leitor no processo de significação do texto ficcional em A Rainha dos Cárceres da Grécia, de Osman Lins. A partir dos bastidores da interpretação proposta pelo narrador ao romance homônimo de sua falecida amante, será mostrado como, à medida que a busca pela intencionalidade autoral sai de cena, evidencia-se o caráter criativo da leitura literária. PALAVRAS-CHAVE: Papel do leitor, significação, Osman Lins.

ABSTRACT: This paper aims to reflect on the role of the reader in the process of signification of Osman Lins' A Rainha dos Cárceres da Grécia. By analyzing the narrator's interpretation of the homonym novel, written by his former lover, it will be shown how, when he is no longer concerned with the search for her authorial intention, the creativity of the literary reading becomes evident.

KEY WORDS: role of the reader; signification; Osman Lins.

A Rainha dos Cárceres da Grécia, de Osman Lins, configura-se como um convite para refletir sobre alguns temas caros à teoria literária contemporânea. Dentre eles, é possível destacar o papel desempenhado pelo leitor na atribuição de sentido ao texto ficcional, sobre o qual esse artigo irá se debruçar. Porém, antes de mostrar como essa questão ganha forma nessa obra do escritor pernambucano, cabe apresentá-la em linhas gerais.

Publicado em 1976, o livro é marcado pela justaposição de gêneros e retrata a leitura literária em suas diferentes facetas. Nele, o narrador, um professor anônimo de Ciências Naturais, escreve, em forma de diário, suas observações sobre o romance homônimo de sua falecida amante, Julia Marquezim Enone, que não foi publicado. A reflexão proposta neste estudo tomará como base as etapas da análise desse leitor ficcional, na qual a busca pela intenção da autora é gradativamente substituída por uma pluralidade interpretativa que destaca o teor de coautoria subjacente ao ato de ler.

Ao deter-se nesse relato (que narra a inglória saga da protagonista Maria de França em busca de um auxílio-doença), o narrador adota, primeiramente, uma abordagem baseada em um suposto paralelo entre o texto de Julia e a quiromancia. Essa leitura, que terá um lugar de destaque, surge quando, ao ir até uma biblioteca investigar a origem dos nomes dos personagens, ele sente estar próximo de uma revelação quase epifânica ${ }^{2}$. Descobre então que vários nomes remetem a famosos videntes e quiromantes e estabelece uma relação entre os capítulos do livro e o significado de cada dedo da mão.

Após estabelecer essa interpretação, o professor pondera sobre o quanto a analogia, percebida por ele após muito esforço e várias releituras, não seria subtraída aos leitores

Doutora em Teoria e História Literária pela Universidade Estadual de Campinas - Campinas. Este artigo é parte de uma pesquisa de doutorado financiada pelo CNPq. Contato: carolinaddf@yahoo.com.br.

"Caminhava para uma revelação - ao menos, para uma hipótese -, devida apenas ao acaso (ninguém mereceu confidências de Julia M. Enone envolvendo seu curioso projeto literário), ou, sendo mais preciso, aos indícios distribuídos por ela e que desempenham, no romance, função idêntica à do conceito nas charadas pitorescas" (LINS, 2005, p. 35). 
de modo geral: “A resposta será afirmativa e indica-nos, a partir do traçado inicial da obra, a lei fundamental da arte da escritora, arte a que se pode atribuir, no mais alto e fino sentido do termo, o título de hermética, não por ser impenetrável, mas por ser uma arte que se oculta" (LINS, 2005, p.52).

Julia seria partidária de uma arte hermética, termo que, em uma de suas acepções hoje menos usuais, reporta-se às artes ocultas, especialmente à alquimia. Ele não considera, entretanto, o livro impenetrável, ressaltando apenas seu caráter velado e a dificuldade de acesso. Com efeito, a relação dos capítulos com a quiromancia, embora obscura, estaria ao alcance de poucos leitores "iniciados", como ele.

Essa leitura, com forte teor místico, vincula-se à questão da intencionalidade autoral, pois, aos seus olhos, a obra da escritora parece então se configurar como uma grande charada, cuja solução se daria a partir de pistas deixadas por Julia ao longo de seu texto. Ou seja, o romance teria um sentido final, conhecido e determinado por ela.

Winsatt e Bearsdley (2002), em "A falácia intencional”, ajudam a elucidar por que, nesse livro de Osman Lins, o anseio de desvendar o sentido pretendido pela autora associa-se a uma arte adivinhatória. Ao questionarem a serventia de perguntar a um autor o que ele quis dizer em sua obra, observam:

Nossa opinião é que a resposta para uma tal pergunta nada tem a ver com o poema "Prufrock"3, pois esta não seria uma pergunta crítica. As perguntas críticas, contrariamente às apostas, não são respondidas desta maneira. Não são resolvidas pela consulta a um oráculo. (BEARDLEY; WINSATT, 2002, p.655)

Descartam completamente a importância do sentido pretendido pelo escritor, pois pressupõem que apenas os elementos textuais devem ser considerados ${ }^{4}$. A busca por essa intenção original, que para eles não deveria integrar uma abordagem crítica, é associada à tentativa de decifrar um oráculo. Em uma frente teórica distinta, Barthes (2004, p. 68-69) também reforça o caráter quase religioso desse tipo de abordagem. Para ele, uma das repercussões do abalo da autoria é deixar de acreditar em um sentido último, “de certo modo teológico (que seria 'a mensagem' do autor-Deus)...." Essas considerações evidenciam o paralelo entre crítica biográfica, intencionalidade e misticismo. Assim, o trecho abaixo, escrito logo após sua "descoberta" da analogia entre a estrutura do romance e as linhas da mão, não causa estranhamento:

Vejo, num filme documentário, desenhos escavados em certa planície do Peru, desértica - uma aranha, um pássaro, um pavão -, de tais proporções que só de boa altura, em vôo, os identificamos. Pode o homem andar a vida inteira por cima desses sulcos, sem jamais supor que integram uma figura harmoniosa, traçada com sabedoria. Deseja-

O comentário de Winsatt e Bearsdley toma como base o poema "Prufock", de T. S. Eliot.

Por mais que a proposta dos críticos americanos seja bastante distinta do pensamento de Barthes e Derrida, utilizado em outros pontos deste artigo, a menção ao New Criticism se justifica, pois todos os autores mencionados partem de uma base epistemológica comum: a diminuição do papel tradicionalmente atribuído ao escritor. Assim, embora cada movimento teórico em questão apresente características específicas, todos são marcados por uma relativização da abordagem intencionalista autoral. 
riam, os que conceberam e imprimiram no solo pedregoso tão perturbadoras imagens e que, sem asas, nunca puderam vê-las -, significar que a ausência de sentido, nas obras de arte ou na vida, pode ser enganosa e advir das nossas limitações? (LINS, 2005, p.50)

O professor faz referência aos desenhos de Nazca, que têm ampla dimensão e só foram descobertos quando a região foi sobrevoada pela primeira vez. A origem dessas figuras é enigmática, possibilitando especulações das mais diversas ordens: não se sabe com qual finalidade foram traçadas e alguns até sustentam a hipótese de elas terem sido desenhadas por extraterrestres. Ao aludir a essas imagens, ele sugere a existência, nos textos literários, de um sentido maior, oculto, o qual estaria, muitas vezes, fora do alcance de quem lê. O escritor, portanto, teria estabelecido, "com sabedoria", um desenho bem delineado e caberia ao leitor descobri-lo. Uma vez configurada a visada quiromântica, o desenho de uma mão repleta de símbolos encontrada nos papéis de sua amada começa a merecer a atenção do narrador:

Como se altera, a uma suspeita ou indício novo, nossa visão das coisas e mesmo a intensidade do que vemos! Folheando os papéis deixados por Julia, mais de uma vez tive entre as mãos uma cópia fotostática a que não concedi atenção e cujo original desconheço. Agora, observo esse papel, valorizado pela hipótese a que já me referi. Sobre a mão espalmada que reproduz, enxameiam símbolos herméticos, castelos, minaretes, luas, um cavalo, a flor-de-lis, a roda denteada, espirais e outros seres da geometria. Isto eu sempre vi. Não me apercebera, até então, dos traços a lápis vermelhos, limitando, nas bases dos dedos, as proeminências consagradas a Mercúrio, Sol, Saturno, Júpiter e Vênus. As linhas rubras, antes invisíveis, tornaram-se brilhantes aos meus olhos e denunciam o interesse de J.M.E pela quiromancia. (LINS, 2005, p.49)

A gravura ajudou-o a confirmar o interesse da escritora pelas artes adivinhatórias, em um momento de sua análise em qual esse tipo de confirmação ainda lhe importa. Porém, embora preocupado se seu traçado interpretativo corresponderia aos propósitos de $\mathrm{Ju}^{-}$ lia, a sequência de seu movimento não é a mais previsível: primeiramente, ele cria sua hipótese e só então entende por que ela guardava o desenho em seus arquivos, e não o contrário. Melhor, ele não apenas compreende: as anotações dela sobre a cópia aparecem. Faz um interessante contraponto entre o que sempre viu e as linhas avermelhadas, até então imperceptíveis: devido ao seu novo olhar, as marcas se delineiam e, de certa forma - não parece excessivo dizer -, a suposta intenção da autora não se revela, mas passa a existir. Assim, mesmo quando ainda busca o intuito de Julia, espécie de sentido original e cifrado, já se prepara timidamente o terreno para a participação do leitor.

A observação de Compagnon (1998, p. 50), para quem o lugar dado à intenção é um dos pontos mais polêmicos da teoria literária, é, sem dúvida, acertada. O caráter controverso atinge inclusive a concepção de intencionalidade, ora associada à figura autoral, ora vista como estratégia de leitura, sendo possíveis também imbricações entre ambas. Tendo em vista a primeira ideia de intenção, predominante nas passagens de A Rainha dos Cárceres da Grécia aqui destacadas, é importante ressaltar que raramente 
é possível ter acesso aos propósitos do escritor. Mesmo nos casos em que ele se manifesta detidamente sobre a interpretação de seus escritos (em entrevistas, por exemplo), a pergunta se coloca: seu posicionamento sobre a obra também não é passível de interpretação? A esse propósito, a observação de Terry Eagleton é bastante pertinente: “A intenção de um autor é, em si mesma, um 'texto' complexo, que pode ser debatido, traduzido e interpretado de várias formas, como qualquer outro" (1997, p. 95).

A proposta do crítico inglês de entender a intenção do autor como um texto passível de interpretação evita reducionismos. De fato, a abordagem que privilegia a intencionalidade, além de bastante especulativa, atribui à obra um caráter excessivamente circunstancial. Se esta for lida principalmente como um reflexo daquilo que seu criador quis dizer, essa suposta voz, muitas vezes metáfora do contexto e da trajetória pessoal, tende a ficar mais tênue com o passar dos anos. Entretanto, em uma concepção que associa o sentido aos signos linguísticos e à leitura, os textos literários são constantemente ressignificados pelo leitor, que os faz assumir diversas formas ao longo do tempo. Essa visada ganha gradativamente destaque em A Rainha dos Cárceres da Grécia, à medida que a busca pela intenção de Julia vai perdendo espaço:

Seria Rônfilo Rivaldo, para a sua criadora, mais claro do que para mim? Não afirmaria que sim e nem ser isto indispensável. Errôneo atribuir ao poeta as mesmas leis que comandam o pensamento abstrato. Está em Lautréamont: “Uma ideia existe para a poesia. Não é a mesma da filosofia”. (LINS, 2005, p.59)

Aqui, ao invés de tentar descobrir a mensagem cifrada da escritora, o narrador questiona se ela teria mais clareza do que ele sobre um de seus personagens. Ele relativiza a importância da resposta, assinalando os problemas de recorrer ao raciocínio intelectual para entender as manifestações artísticas - nas quais as perguntas podem ser respondidas de diversas formas, embora nunca de modo definitivo. No entanto, apesar dessas observações, a sombra da supremacia interpretativa do autor sobre sua obra somente vai perder força quando ele assumir o caráter criativo inerente à leitura literária. Nesse sentido, são fundamentais as passagens que legitimam o papel da imaginação.

o tópico aparece a partir da teoria de Anaximandro de Mileto para explicar o relâmpago e o trovão. Segundo ele, ambos seriam o resultado do rompimento do vento contido nas nuvens, como vinho no odre. O narrador frisa que a explicação, mesmo invalidada pela ciência, subsiste graças ao seu teor imaginário: quem pensa pode tomar como "produto da razão algo engendrado pela invenção..." (LINS, 2005, p. 90-91), como ocorreu com o filósofo. Por isso, grande é a vantagem de quem imagina: "Se imagino, entretanto, nunca me engano: o imaginário é autônomo e plana sobre as mudanças" (LINS, 2005, p. 90). A referência à proposta de Anaximandro tem desdobramentos:

Concentro-me num aspecto do livro e nem sempre estou certo do que penso ver. É o caso de algumas correspondências - para mim bastante nítidas, afetando a história e o discurso - que ligariam Maria de França ao escritor. [...] 
A aproximação que menciono e ilustro é um exemplo entre outros. Terá razão de ser, ou eu a inventei? Não mais me oprime o dilema. Alguma coisa eu teria de aprender com os relâmpagos de Anaximandro. (LINS, 2005, p.91 - 92)

O professor de Ciências Naturais instaura um paralelo entre a protagonista e a figura do escritor, explicitando seu incômodo por não estar certo de sua pertinência. Mesmo se as dúvidas perpassam vários pontos de sua análise, elas não causam tanto mal-estar como aqui, pois o que está em jogo não são meras veredas interpretativas, mas a pretensa compatibilidade de sua leitura com os intuitos de Julia. Diferentemente de uma passagem anteriormente citada, nesta os seus paralelos são nítidos, e não as marcas da escritora sobre o desenho, que, aliás, ganharam forma somente após ele ter montado sua interpretação. A transição do trecho remete indiretamente a essa distinção: idealizadas por Julia ou criadas por ele a partir do texto, as correspondências entre a protagonista e o escritor existem. Quando o impasse de a aproximação ter sido prevista ou inventada por ele se dissipa, não se sente mais oprimido pois, ao romper as amarras da intenção autoral, passa a desfrutar de certa liberdade criativa diante da obra.

O fato de essa "lição" sobre a importância da imaginação ter sido aprendida com Anaximandro é bastante elucidativo: em sua época, diante da escassez de recursos para entender os fenômenos atmosféricos, imagina uma explicação sobre a origem dos raios e trovões. De certo modo, o narrador, diante da suposta intenção da escritora, de tão difícil apreensão e igualmente fora de seu alcance, não estaria reproduzindo o mesmo movimento? Seja como for, ele descarta a tentativa de desvendar e passa a criar.

Sua mudança de atitude diante do texto não impede, entretanto, que a intencionalidade esteja presente em momentos posteriores de suas notas, como, por exemplo, quando alude à escrita "cheia de intenções e subterfúgios" de Julia (LINS, 2005, p.106). Diante das reflexões anteriores, porém, nessa aparente reincidência, restrita a trechos esparsos, parece estar em questão outra ideia de intenção, associada a uma estratégia de leitura (cf. COMPAGNON, 1998, p. 50). O modo de o narrador conceber a interpretação literária passou de fato por uma transição, a qual pode ser compreendida com um comentário de Leyla Perrone-Moisés no horizonte:

Para os críticos literários, como para os pesquisadores científicos, a questão que se coloca não é mais a de descobrir, objetivamente, realidades substanciais, mas de inventar relações na "realidade" da obra (assim como a obra inventa relações na 'realidade' do mundo). O que Jean Ricardou coloca muito bem: “Ler é produzir por demonstração relações num texto". (PERRONE-MOISÉS, 2005, p. 24)

Segundo ela, a crítica literária contemporânea abandonou a pretensão cientificista do século XIX e, ao incorporar a criatividade, aproximou-se bastante da arte. Caberia então ao leitor adotar um comportamento similar ao do escritor, pois ambos criam visões próprias ao instaurarem relações tanto nas obras quanto no mundo. Uma nova passagem de A Rainha dos Cárceres da Grécia dá prosseguimento a esta discussão: 
Imitando Julia Marquezim Enone, que consagrava por vezes manhãs e tardes a um parágrafo, aplicação agravada no meu caso pela necessidade de criar artificialmente, com base no exemplo de alguns mestres, aquela espécie de instinto mediante o qual elege o narrador, na multiplicidade do real, fragmentos que, imantados de significações, nos levam a perceber ou a crer que percebemos, à sua luz, mil fatores ausentes do texto (o fundo implícito do texto), concluí no sábado o trecho datado de 26 último, nele aplicando perto de dez dias. (LINS, 2005, p.123)

Vale frisar sua descrição da experiência literária: todo autor de um texto ficcional seleciona fragmentos significativos e, a partir deles, o leitor vislumbra "mil fatores ausentes do texto". Aplicando essa reflexão ao romance em questão, não mais importa se o narrador percebeu a suposta mensagem da Julia Marquezin Enone, mas sim o fato de ele criar significados potencialmente sugeridos pelo "fundo implícito do texto". O foco agora não recai apenas na obra, mas no seu papel diante dela.

Passa a ser objeto desta análise o quanto o escritor tem consciência dos sentidos desencadeados por seu texto. Quando o professor conhece o ex-marido de Julia, que não tem uma das mãos, cria hipóteses para entender a suposta relação entre o órgão mutilado e o fundo quiromântico do romance, sem chegar a conclusões. Chama a atenção seu modo de lidar com o impasse: "Outras suposições surgem e lutam. Mas a verdade, afinal, não chega a importar muito. Seja qual for (mesmo Julia teria a resposta?)..." (LINS, 2005, p.124). Após relativizar a importância de encontrar uma verdade definitiva, cogita se a autora saberia mais do que ele sobre a gênese de $A$ Rainha dos Cárceres da Grécia, desfazendo a hierarquia entre ambos. As considerações de Derrida sobre o processo de significação aumentam o alcance desse comentário. Antes de citá-las, porém, é necessário contextualizar sua noção de "suplemento".

Em Gramatologia (DERRIDA, 2004), mostra como Rousseau, apesar de suas inúmeras ressalvas à escrita, recorre a ela. O escritor faz essa opção por acreditar que a fala não lhe permite expressar seu verdadeiro valor, mesmo considerando a escrita como uma adição artificial, um mal necessário. Ela seria então um intermediário entre a presença e a ausência totais, marcado pela necessidade de substituir o insubstituível. Ou seja, um suplemento à fala. Embora bastante simplificado, esse esboço do pensamento de Derrida permite acompanhar algumas de suas observações especialmente relevantes aos propósitos desta reflexão. O suplemento faz com que

[...] o sujeito presumido da frase diga sempre, servindo-se de "suplemento", mais, menos ou coisa diferente do que ele quereria dizer. Portanto, essa questão não é somente da escritura de Rousseau, mas também de nossa leitura. Devemos começar por considerar esta presa ou esta surpresa: o escritor escreve em uma língua e em uma lógica que, por definição, seu discurso não pode dominar absolutamente o sistema, as leis e a vida própria. Ele dela não se serve senão deixando-se, de uma certa maneira e até um certo ponto, governar pelo sistema. E a leitura deve, sempre, visar uma certa relação, desapercebida pelo escritor, entre o que ele comanda e o que ele não comanda, dos esquemas da língua que faz uso. Esta relação não é uma certa repartição quantitativa de sombra e de luz, de fraqueza ou de força, mas uma estrutura significante que a leitura crítica deve produzir. (DERRIDA, 2004, p.193-194) 
O autor, portanto, não tem controle absoluto sobre o sistema de signos linguísticos de que se vale para escrever, o qual assume "vida própria". A leitura deve produzir uma estrutura significante, cujo intuito não é reproduzir “a relação consciente, voluntária, intencional, que o escritor institui nas suas trocas com a história à qual pertence graças ao elemento língua" (DERRIDA, 2004, p. 194). Em A farmácia de Platão (1997), o filósofo lança luz sobre essa cadeia de signos:

Essas comunicações, esses corredores de sentido, Platão pode por vezes declará-los, clareá-los, neles jogando "voluntariamente" [...]. Do mesmo modo, Platão pode, em outros casos, não ver as ligações, deixá-las na sombra ou interrompê-las. E, no entanto, essas ligações operam-se por si mesmas. Apesar dele? Graças a ele? Em seu texto? Fora de seu texto? Mas onde então? Entre seu texto e a língua? Para qual leitor? (DERRIDA, 1997, p.43)

Derrida acredita ser impossível responder a essas perguntas, o que o faz desconfiar do quanto são pertinentes. Porém, ao afirmar que as ligações operam-se por si mesmas, independentemente do como se estabelecem e do grau de consciência do escritor e do leitor em relação a elas, leva a crer que sua existência não está em questão. A imagem de "corredores de sentido" é particularmente interessante, pois tira de cena o ponto de origem e destino, privilegiando o processo. Essa mesma ênfase se faz presente no pensamento de Barthes (2004, p.41), para quem o leitor, ao colocar a leitura "em roda livre", "não decodifica, ele sobrecodifica; não decifra, produz/amontoa linguagens, deixa-se infinita e incansavelmente atravessar por elas: ele é essa travessia”. A abertura interpretativa ganha espaço nas notas do narrador de $A$ Rainha dos Cárceres da Grécia, nas quais a noção da obra como deflagradora de sentidos torna-se de mais em mais predominante:

Que significa, no romance, a redução de tantos mitos brasileiros à cinzenta vida burocrática? Que significa a transformação de Ulisses num insignificante morador de Dublin? Respostas solicitam o observador. Corretas? Não. Não há, nesse caso, respostas absolutas, e sim respostas possíveis. Nem mesmo o autor é testemunha incontestável: ele não domina integralmente a sua criação, na qual subsistem componentes obscuros. Isto não impede de arriscarmos hipóteses de impossível confirmação. O importante é que elas sejam apreciadas como um testemunho da atuação da obra no espírito do observador, e não como decifração que a reduza a uma mensagem cifrada - limitada, portanto - , contrariando a natureza do objeto artístico, que nunca é um detentor de significação, e sim um deflagrador de significações.

Isto, ainda que ele, no espírito do criador, se revista de uma significação precisa. (LINS, 2005, p.185-186)

Sua reflexão, desencadeada pela transformação de diversos heróis nacionais em burocratas no romance, sintetiza elementos anteriormente analisados. Ele abandona definitivamente a concepção da obra como uma mensagem cifrada, passando a encará-la como fonte de significações possíveis, mas nunca definitivas ${ }^{5}$. Essa nova visão o leva a fazer, nas

Aproxima-se então de Barthes, quando este afirma que "o escritor se aplica em multiplicar as significações sem as preencher nem fechar, e utiliza a linguagem para constituir um mundo enfaticamente significante, mas finalmente jamais significado" (2004, p.174). 
linhas seguintes, uma espécie de "declaração dos direitos universais do leitor": "Assim, é resguardado pela minha liberdade de leitor, e sem fechar-me a outras interpretações, que suponho haver no motivo discutido um intuito corrosivo ou mesmo uma agressão" (LINS, 2005, p.186). Algumas páginas depois, desponta outra legitimação da leitura:

Eu, quem eu seja, quero ver - e, vendo assim, vejo e faço ver de uma certa maneira a romancista - quero ver nos loucos do romance, na clausura dos loucos, principalmente, o lado negro e cru do ofício de escrever, a condição do escritor em algum país onde só se tolera o seu ato essencial quando esvaziado de sentido e onde, se admitido à convivência dos sãos, é sob vigilância e em caráter provisório, como esses retardados que vêm passar em casa o Natal. (LINS, 2005, p.198)

Ao explicar por que os colegas de Maria de França representam diversos escritores da literatura brasileira, o professor deixa claro que, quando quer ver um cotejo, ele não só o vislumbra como o torna visível. Chega inclusive a fazê-lo existir. Essa afirmação evidencia o potencial do leitor, capaz de criar relações a partir do texto, as quais passam a existir e a fazer parte do romance em questão. É importante destacar seu argumento de que, mesmo se o escritor tinha um propósito em mente, a obra o ultrapassa:

Teu livro, Julia, começa lentamente a fechar-se para mim. Sei e tu sabias tão ilimitadas serem as obras quanto limitado o nosso alcance. Por isto buscam as obras encarnações mais perduráveis que os homens e, num certo sentido, indestrutíveis: para que muitos espíritos, sucessivamente, aguilhoados pelos segredos infindáveis da obra, possam acumular decifrações. [...]

Mas como entender, silenciosa amiga, que a mente restrita do artesão venha a conceber e terminar um produto cuja magnitude nos suplanta? É a obra, e não ele, circunscrito como nós, que sabe mais do que todos. (LINS, 2005, p.228)

Fica evidente, entretanto, que o texto ficcional também é maior que seu leitor, se considerado individualmente. Por isso, é discutível o posicionamento de Compagnon (1998, p. 57), quando questiona o alcance da "morte do autor". Segundo ele, esse movimento talvez se restrinja a uma mera troca do autor pelo leitor, ou, segundo o exemplo empregado pelo teórico, baseado em uma leitura um tanto distorcida do conto de Borges, de Cervantes por Pierre Menard. Sua colocação, além de ser marcada por um apego excessivo à posição autoral - passível de ser substituída, mas não eliminada -, desconsidera que, para os teóricos dessa vertente, o leitor é despersonalizado. Barthes faz questão de mostrar a diferença entre essa figura e um indivíduo específico: "o leitor é um homem sem história, sem biografia, sem psicologia; ele é apenas esse alguém que mantém reunidos em um único campo todos os traços de que é constituído o escrito" (2004, p. 70). Ou seja, lida com uma abstração, um lugar vazio a ser ocupado por várias pessoas, embora jamais de forma completa ou ideal.

A última passagem de A Rainha dos Cárceres da Grécia citada, por um lado, reforça mais uma vez que o escritor cria algo cuja compreensão lhe escapa, pois sua escrita contém potenciais desdobramentos que não estão ao seu alcance. Em contrapartida, 
propõe que o professor de Ciências Naturais, representação do leitor real, tenha um alcance tão limitado quanto o de Julia face ao seu romance. O potencial semântico do texto ultrapassa, pois, tanto a figura do autor quanto a do leitor empírico.

A imagem da obra em busca de "encarnações mais perduráveis do que os homens" é especialmente profícua e instaura um paralelo entre a escrita e morte: o escritor falece, os sinais de sua biografia tornam-se imprecisos ou desaparecem com o passar do tempo; porém, seu texto, à revelia do sentido por ele pretendido, permanece vivo, ganhando novas formas, versões, enfoques. Assim, quando a busca por decifrar a intenção do autor é deixada de lado, ganha espaço um novo tipo de transcendência, não mais ligada ao misticismo do sentido final: a obra transcende o indivíduo por sobreviver a ele e, ao "encarnar" em diversos leitores, é ressignificada segundo a experiência e o contexto de cada um. Uma derradeira passagem presta-se a encerrar esta reflexão:

O homem que remove a terra acumulada sobre uma civilização e interroga as suas ruínas assemelha-se aos que, recusando o mundo inesgotável, curvam-se ante uma obra de arte e tentam penetrá-la. A diferença entre um e outro é que a civilização exumada talvez se esgote um dia. (LINS, 2005, p. 225)

Quem se debruça sobre um texto ficcional é comparado a um arqueólogo diante das ruínas de uma civilização qualquer. No entanto, o peculiar livro de Osman Lins, ao descartar a ideia de sentido final e reforçar o papel criativo do leitor no processo de significação, lembra que a comparação tem limites: a obra literária, graças ao seu potencial simbólico, é inesgotável.

\section{Referências Bibliográficas}

BEARDSLEY, Monroe; WINSATT, Willian. "A falácia intencional”. In: LIMA, Luiz Costa. A teoria da literatura em suas fontes. Vol. 2. São Paulo: Civilização Brasileira, 2002.

BARTHES, Rolland. O rumor da língua. São Paulo: Martins Fontes, 2004.

COMPAGNON, Antoine. Le démon de la théorie. Paris: Seuil, 1998.

DERRIDA, Jacques. A farmácia de Platão. São Paulo: Iluminuras, 1997. . Gramatologia. São Paulo: Perspectiva, 2004.

EAGLETON, Terry. Teoria da Literatura: uma introdução. São Paulo: Martins Fontes, 1997. LINS, Osman. A Rainha dos cárceres da Grécia. São Paulo: Companhia das Letras, 2005. PERRONE-MOISÉS, Leyla. Texto, crítica, escritura. São Paulo: Martins Fontes, 2005.

ARTIGO RECEBIDO EN: 19 ago. 2012

ArTigo ACEITO EM: 12 set. 2012

Referência eletrônica: DAmasceno, Carolina Duarte. O leitor e as mudanças no processo de significação: uma análise de A rainha dos cárceres da Grécia, de Osman Lins. Revista Criação \& Crítica, n. 9, p. 72-80, nov. 2012. Disponível em: <http://www.revistas.usp.br/criacaoecritica>. Acesso em dd mmm aaaa. 